Proceedings of the Seminar on the Social and Economic Effects of Earthquake Prediction, 12 October, 1977.

\title{
MITIGATION OF DANGER TO PROPERTY
}

\section{M. Strachan*}

\subsection{GENERAI}

To comply with above title, it is essential to subdivide the paper into two major areas:

\section{(a) Design of New Construction \\ (b) Existing Construction}

Some brief comments are therefore made on new construction which is now designed with more experience of earthquakes available.

Existing construction is a different problem entirely because the general form of construction used in the earlier years of our building operations (brick bearing wall, cast iron columns, timber floors with a lack of connections), was imported from Europe. This form of construction is totally inadequate to resist earthquakes and therefore some ingenuity is needed to overcome these weaknesses. Nevertheless, buildings have been strengthened at a moderate cost, certainly to resist moderate earthquakes and some details are discussed later in the paper.

\subsection{NEW CONSTRUCTION}

The comments contained in this section of the paper are intended to point out some of the major areas that need to be covered in current design and construction.

\subsection{Current Codes}

The current codes take due account of the requirements for earthquake design and if these are followed, new construction should normally be satisfactory to resist earthquakes. Indeed there are many who now feel that there is overdesign for earthquake resistance incorporated in the present codes in use in this country.

However, even by using the codes we can achieve large variations in the designs and individual preferences can be used. Whatever method is used, it must be remembered that the structure is only as good as its weakest link. Therefore, the total structure including non-structural elements needs to be checked for performance.

\subsection{Choice of Materials}

The choice of materials will generally depend on the current costs at the time of design. Certainly the height factor is a major consideration, just as use of local materials, availability of labour, likelihood of industrial strife, etc. All need to be considered.

\subsection{Symmetry}

There is no substitute for symmetry in

* Consulting Engineer, Wellington. structural design to give satisfactory performance. There are enough variables which affect performance without having unsymmetric buildings.

It is unfortunate that all designers are often faced with coping with designs which they do not really like. Outside influences of which the major one is cost, dictate these designs.

\subsection{Separation}

Separation of structures to avoid the banging together with adjacent structures is essential. This fact is now generally accepted in new construction but there are still many buildings being constructed, such as extensions, which are joined together, whereas their performance would be much more predictable if they were separated.

\subsection{Foundations}

Foundation conditions are very important and an adequate knowledge of the foundation soils needs to be known either by investigation or experience. The possibility of liquefaction of soils is vitally important and is an area where much of New Zealand is suspect. One of the major examples of liquefaction was the Niigata earthquake of 1964 in Japan in which major damage occurred. Not enough account is being taken of this phenomenon in this country today. There is plenty of evidence of concern with the superstructure, but the structure is only as good as its foundations.

It is interesting that the N.Z. Code on Foundations had a draft section on liquefaction included prior to the Niigata earthquake. This earthquake made the Japanese take much more account of foundation design. We shouldn't need a similar occurrence here for our designers to take greater care in foundation design. The designer must remember that he takes the ultimate responsibility for his building design.

\subsection{Superstructure}

A tremendous amount of experimental work has been carried out in the design of joints, etc. for earthquake resistance. However, we must not lose sight of the fact that some of the criteria required for high rise developments can be too severe in low rise buildings. We must also look at the buildings which have survived an earthquake as well as those which have been damaged.

\subsection{Architectural}

Structural designers are now well aware that design for earthquakes needs to go much further than the basic structure. Windows, suspended ceilings and other features which are normally in the architect's field 
have behaved badly in earthquakes. This needs to be continually re-emphasised to architectural clients even though most architects are now aware of the problem.

However, it is even more essential that manufacturers and suppliers be made, by our specifications, to deal with this problem. Too many manufacturers and suppliers have two different designs available and unsatisfactory designs are still being incorporated in new buildings.

\subsection{Building Services}

Building services need to be designed to allow for seismic movement. Too often in the past, disruption has occurred because individuál units were not tied back to the structure. Failure of telephone exchanges has occurred because batteries overturned. Many electrical installations include brittle components and these need to be carefully designed for good performance.

Sewerage and stormwater pipes need to be designed to allow for the forces involved. Due account should be taken of the ground in which services are laid. Some services have collapsed, for instance, because there is no allowance for movement where services leave the ground and are slung under a bridge for a water crossing.

Spaceheaters need to be well tied. Movement and overturning could occur in an earthquake and we all remember that it was the fire and not the earthquake which caused most damage in Napier in 1931 and also San Francisco in 1906.

Unreinforced brick chimneys have, of course, behaved unsatisfactorily in earthquakes. We have even seen aftershocks demolishing the new replacement chimneys almost as soon as they are repaired.

Even reinforced chimneys have problems where the requirements for earthquake and thermal performance conflict, i.e. at the gathering. A heap of bricks is often easier to deal with rather than a whole section of chimney in one piece. We must be sure that we advance enough to keep pace with the earthquake.

\subsection{Internal Equipment}

Units such as shelving need to be tied back. They have been thrown right across buildings in earthquakes and are therefore dangerous.

Glassware, where practical, should be kept in cupboards. This could be enough to allow it to survive.

\subsection{Exterior Work}

Exterior work, such as fences and walls, are often not looked at by the structural designer and these have also behaved unsatisfactorily in earthquakes. Even a garden wall today is an expensive item and a little more thought at the design stage would help it survive.

\subsection{Supervision}

It is also essential that construction be adequately supervised. There is also too much emphasis at the present time being placed on design and not enough on supervision. In many cases construction is proceeding with little or no supervision. If economic construction is achieved by this method, it is poor economics.

A structure doesn't know that it is supposed to behave in a certain manner and it won't if a weak construction joint interferes with the theoretical philosophy. For instance, reinforced concrete means just that, and there should be room to place the concrete.

\subsection{CIVIL WORK}

Roading, railways, marine works, etc. have all behaved unsatisfactorily in earthquakes. Large scale slipping of materials has occurred and has taken days or weeks to repair vital links with the outside world.

There is not enough emphasis placed on the future performance of filis when associated with these works. This applies particularly where filling is carried out underwater. Fine grained soils are not being compacted in this situation and compaction under the weight of the fill could take many decades before the fill is dense enough to perform satisfactorily.

The design of bridging to resist earthquakes after a slow start has made substantial progress over the last decade. Nevertheless, the same criteria apply; good design and well supervised construction are essential.

\subsection{EXISTING CONSTRUCTION}

For a moderate cost, future damage to existing buildings could be minimised by removing or dealing with undesirable features. These include renoval of heavy unreinforced parapets, providing additional seismic resistance such as shear walls, cross tieing, additional foundation work and the like.

Carrying out this work may mean that the structure will survive a smaller earthquake without damage whereas it would have been damaged if the alterations had not been carried out. Subsequent disruption at the time of the earthquake could cause increased costs.

\section{I Strengthening}

Following are some of the methods used to strengthen buildings for earthquake resistance:-

\section{(i) Steel Frames}

These have been used in two ways:-

(a) Where the steel frames have been used externally with the use of cross ties at floor and roof levels to try to hold the building together. (Fig. I.)

(b) Where a steel frame has been used internally to hold up the floors in the event of a collapse of the external brick walls.

(ii) Concrete Erames 
These have also been used in two ways:-

(a) Where the frame has been stiffened by the addition of extra concrete and ties around columns and beams. (Figs. $2 \& 3$.

(b) Where an external frame of concrete has been used.

\section{(iii) shear walls}

Shear walls have been used, both internally and externaliy, to improve the seismic resistance of buildings.

All the methods quoted have some advantages and disadvantages and each should be considered when strengthening is proposed.

\subsection{Performance of Strengthened Buildings}

By far the best examples of performance of strengthened buildings to resist a moderate earthquake are those in the Gisborne City that were strengthened after the Napier earthquake in 1931 and suffered a moderate earthquake on $5 \mathrm{March}$ 1966. It is understood that this is the only case in the country in which a substantial number of strengthened buildings have resisted a moderate earthquake.

The author was fortunate to have checked the Government Buildings in Gisborne for seismic resistance only 9 days before the earthquake, and also to be sent back by car, arriving in Gisborne some 14 hours after the main shock. Buildings which were inspected both prior to and after the earthquake contained all the forms of strengthening mentioned above. Full details of report of individual buildings are contained in Bulletin 194 of the Department of Scientific and Industrial Research entitled Gisborne Earthquake N.Z. March 1966 (1).

The conclusions contained in the paper by the author and $O$. A. Glogau bear repeating and in particular conclusion 4.

"Strengthening of older type buildings is practical if resistance to moderate type earthquakes can be achieved. In the 1966 earthquake the performance of buildings strengthened (after the 1931-32 earthquakes) with flexible steel members was not good. On the other hand, in buildings in which rigid concrete encased steel was used, no further damage occurred."

The author believes that strengthening of old brick buildings is therefore better if carried out using concrete frames or encased structural steel to provide a rigid member which will take load concurrently with the brickwork.

However, the author further believes that the use of steel frames internally to support the floors (where they are timber) is the cheapest form of strengthening and is also valid.

\subsection{Strengthening of Non-Structural Elements}

It follows therefore that the strengthening, by tieing back or some other method, of non-structural elements can also be a worthwhile exercise.
It is good policy for an owner to have a full record of the defects in his building, which is updated periodically (preferably after each significant earthquake) so that he is in a position to accurately justify claims after an earthquake. Otherwise an owner is in a weak position to argue with the Insurance Assessor.

This, of course, brings up the question of adequate insurance cover. The owner, of course, should obtain annual valuations to his property for insurance purposes.

Insurance should be on replacement value rather than indemnity and care should be taken with the valuation. Under-valuation means that there will be increased costs for replacements and over-valuation means that the owner is paying out good money for nothing.

\subsection{SUMMARY}

Remember that because a structure survives one earthquake does not mean that it will survive the next. All earthquakes are different. You are all aware that buildings often leak when the wind is in one quarter only. A similar philosophy applies to earthquakes.

There are many areas in which owners can do more to mitigate earthquake damage. The moderate cost involved will generally be money well spent when the next earthquake arrives.

\section{REFERENCES}

1. Report on Damage in the Gisborne Earthquake, 1966. C. M. Strachan and O. A. Glogau. N.Z. Department of Scientific and Industrial Research Bulletin 194. Appendix. Detailea Report on Buildings - C. M. Strachan.

\section{DISCUSSION}

Mr. Glogau raised the problem of strengthening buildings of historic or aesthetic value. He pointed out that it was very difficult to provide long term protection for these buildings because the longer the term of retention the greater the chance of a very severe earthquake and hence the need to provide a higher level of protection.

\section{Professor Evison stated that he} believed that in the area affected by the prediction the community would respond by doing as much as possible to mitigate the effect of the earthquake but it would be highly unlikely that local building industry resources would be able to deal with the volume of work required for the strengthening of buildings and protection of public services. He expressed the hope that this seminar would encourage forward planning by the community in this important area. Mr. Strachan agreed and further emphasised the need for the owners of buildings to be made aware of the level of protection a particular building strengthening scheme would provide. Some risk would still remain and the owner should be made aware of the relative risk associated with various levels of protection.

\subsection{INSURANCE RECORDS}




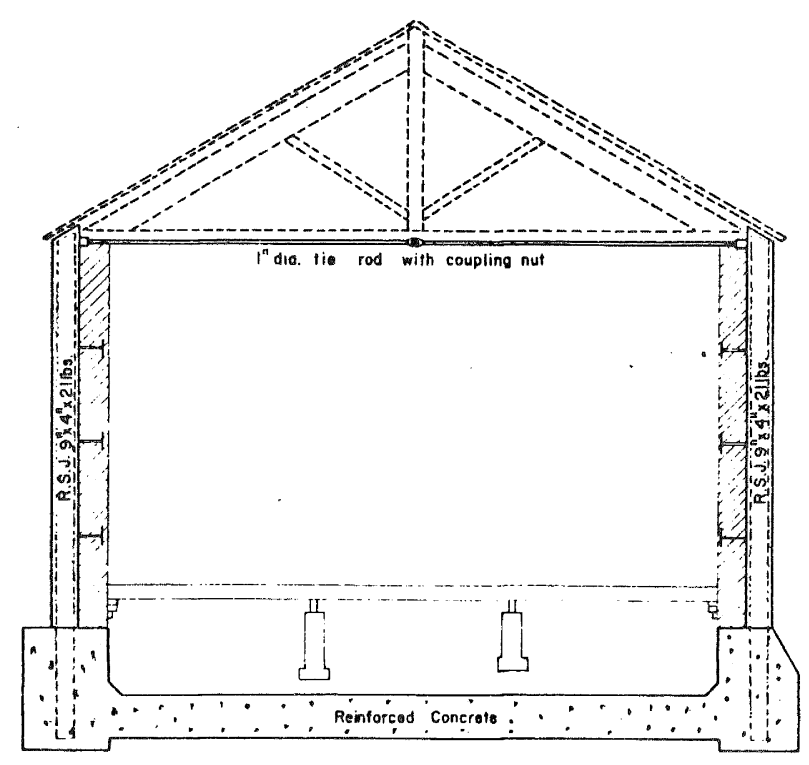

Roinforced Concrote $\because \because$

Brickwork

FIGURE 1: COOK HOSPITAL

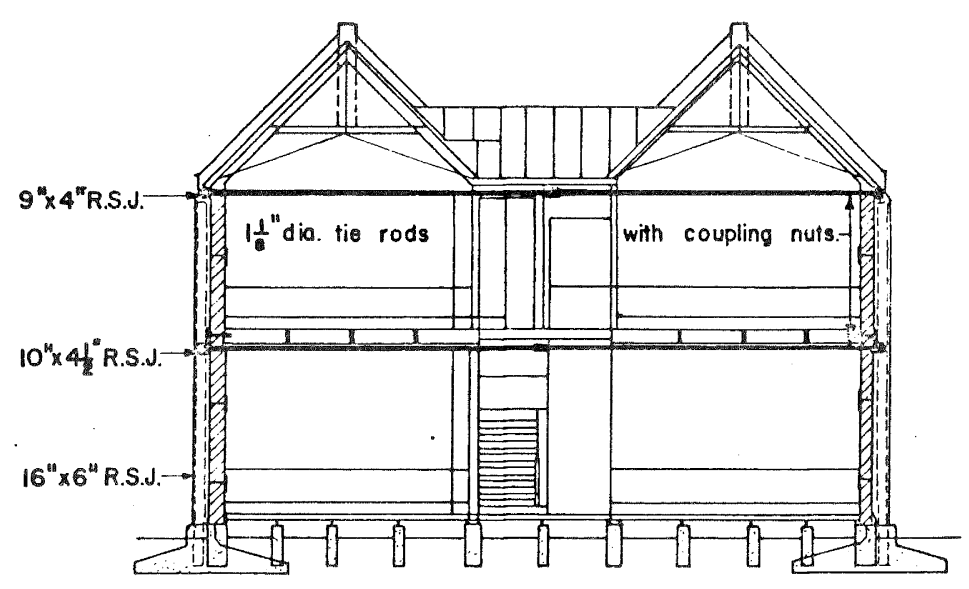

FIGURE 2: ELEVATION SHOWING SYSTEM OF STRENGTHENING CENTRAL SCHOOL AFTER THE HAWKE'S BAY EARTHQUAKES OF 1932

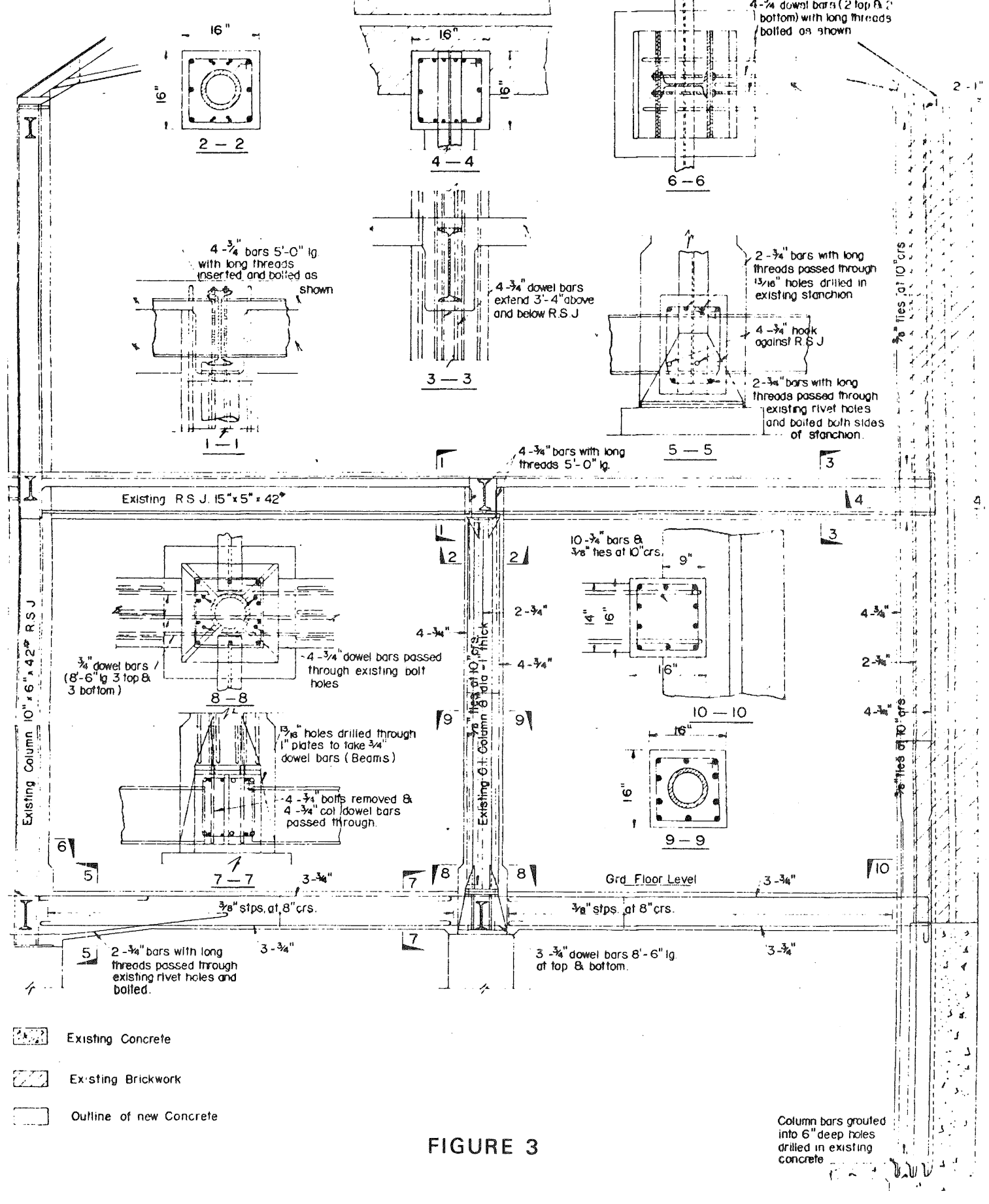

